\title{
COMUNICAÇÃO E EXTENSÃO: RELATO DE EXPERIÊNCIA DA COBERTURA MULTIMÍDIA DA OPERAÇÃO BOROROS - RONDON 2015
}

\author{
Aline Czezacki Kravutschke \\ Universidade Estadual de Ponta Grossa \\ alineczezacki@gmail.com \\ Crystian Eduard Kühl \\ Universidade Estadual de Ponta Grossa \\ cryyskuhl@gmail.com \\ Marcia Boroski \\ Universidade Estadual de Ponta Grossa \\ marciaboroski@yahoo.com.br
}

\author{
Mariele Aparecida Morski \\ Universidade Estadual de Ponta Grossa \\ marielemorski@gmail.com \\ Millena Eduarda Sartori \\ Universidade Estadual de Ponta Grossa \\ millena.sartori@hotmail.com
}

\begin{abstract}
Resumo
Este artigo tem o objetivo de discutir o processo produtivo dos materiais multimídia produzidos durante a cobertura das atividades rondonistas da Operação Bororos - Rondon 2015. Este trabalho tem como método o relato da experiência de estudantes e professores, sob a luz de autores da área da comunicação. A cobertura foi feita pela Equipe de Comunicação Social (ComSoc) da Universidade Estatual de Ponta Grossa, de 10 a 26 de julho, período da Operação, e teve como resultados vídeos, fotos, fotolegendas, gerenciamento de redes sociais, notas e notícias, publicados nos meios de comunicação digital do Projeto Rondon. A atividade da equipe de ComSoc contribuiu, essencialmente, para a prática de técnicas e dinâmicas de produção, próprias da comunicação, e para a divulgação e documentação da atividade extensionista universitária proporcionada pelo Projeto Rondon, bem como a capacitação para o desenvolvimento sustentável das comunidades com compuseram a Operação Bororos.

Palavras-chave: Extensão. Produção Multimídia. Operação Bororos.
\end{abstract}

\section{COMMUNICATION AND EXTENSION: CASE STUDIES OF BOROROS OPERATION MULTIMEDIA COVERAGE - RONDON 2015}

\begin{abstract}
This article aims to discuss the production process of multimedia materials produced during the coverage of the rondonistas activities of the Bororos Operation - Rondon 2015. The method of this study is case studies of students and teachers, under the light of authors in the area of communication. The cover was made by Media (ComSoc) of State University of Ponta Grossa, from 10 to 26 July, operation period, and results videos, photos, photo-captions, social networking management, notes and news published in the media digital of Project Rondon. ComSoc staff activity contributed essentially to practice techniques and production dynamics, own communication, and for the dissemination and documentation of extensionists university provided Project Rondon, as well as capacity building for the sustainable development of the communities with composed the Bororos Operation.

Keywords: Extension. Multimedia coverage. Bororos Operation.
\end{abstract}




\section{COMUNICANIÓN Y EXTENSIÓN: ESTUDIOS DE CASO DE LA COBERTURA MULTIMEDIA DE LA OPERACIÓN BOROROS - RONDON 2015}

\section{Resumen}

Este artículo pretende discutir el proceso de producción de materiales multimedia producidos durante la cobertura de las actividades rondonistas de la operación Bororos - Rondon 2015. El método de este estudio es divulgar la experiencia de los estudiantes y profesores, bajo la luz de los autores en el área de comunicación. La portada fue hecha por los medios de comunicación (ComSoc) Universidad Estado de Ponta Grossa, del 10 al 26 de julio, operación período y resultados videos, fotos, foto captions, social networking gestión, notas y noticias publicadas en los medios de digital Proyecto Rondon. ComSoc personal contribuido esencialmente a practicar técnicas y dinámica de la producción, propia comunicación y para la documentación de actividad difusión y extensionistas universitaria proporcionada por proyecto Rondon, así como capacitación para el desarrollo sostenible de las comunidades con compuesto por la gente de Operación Bororos.

Palavras clave: Extensión. Multimedia. Operación Bororos. 
Comunicação e extensão: relato de experiência da cobertura multimídia da Operação Bororos Rondon 2015

\section{INTRODUÇÃO}

A Operação Bororos - que aconteceu de 10 a 26 de julho de 2015, teve como sede a cidade de Cuiabá e desenvolveu-se em 15 outros municípios - contou com a participação de uma Equipe de Comunicação Social (ComSoc) composta por estudantes e professores do curso de Jornalismo da Universidade Estadual de Ponta Grossa (UEPG). A equipe visitou as 15 cidades, cujas atividades eram desenvolvidas por 30 Instituições de Ensino Superior (IES), e fez a cobertura das atividades rondonistas, incluindo eventos de abertura e encerramento, em Cuiabá. A participação desta equipe justifica-se, primeiramente, para garantir que os rondonistas da ComSoc pudessem aplicar conhecimentos, técnicas e dinâmicas produtivas, próprias da comunicação, de forma a exercer atividade extensionista. A extensão, junto ao ensino e à pesquisa, faz parte do tripé pelo qual se ergue a universidade, e apesar disso, muitas vezes, enfrenta desafios e dificuldades para alcançar a comunidade e retornar à sociedade essa produção de conhecimento.

Além disso, a participação é justificada quando se determina que o objetivo é realizar o registro, de forma multimídia, das atividades rondonistas, produzindo um material ilustrativo acerca da capacitação promovida. Para isso, a Equipe de ComSoc da UEPG percorreu mais de $4000 \mathrm{~km}$, com a seguinte lógica de trabalho: a equipe inteira pernoitou todos os dias em Cuiabá e parte dela (um professor e quatro estudantes) deslocava-se, todos os dias, para uma, duas ou três, das 15 cidades que receberam a Operação. A produção foi pensada a partir de núcleos (audiovisual, fotográfico, redes sociais e textuais) cujas pautas eram decididas conforme programação oficial do Rondon e/ou atividades desenvolvidas pelos rondonistas.

Os estudantes, então, produziram vídeos curtos e diários, um vídeo final, fotografias, fotolegendas, notícias, notas, perfis, releases, gerenciaram as redes sociais durante a operação e fez coberturas em tempo real. Os materiais produzidos foram veiculados no site e no canal do Youtube do Projeto Rondon e divulgados nas redes sociais Facebook e Twitter. É pertinente indicar que essas produções foram orientadas pelos professores e tiveram aprovação prévia da coordenação do Rondon. Portanto, o objetivo deste artigo é discutir o processo produtivo dos materiais multimídia produzidos durante a cobertura das atividades rondonistas da Operação Bororos. 
Comunicação e extensão: relato de experiência da cobertura multimídia da Operação Bororos Rondon 2015

\section{MATERIAIS E MÉTODOS}

A equipe de ComSoc da Operação Bororos foi composta por dois professores e oito estudantes do curso de Jornalismo da UEPG. A seleção destes alunos foi feita seguindo critérios definidos pelo próprio Projeto Rondon e pela banca de seleção: o professor coordenador, o professor adjunto, o professor suplente e um professor rondonista da Pró-Reitoria de Extensão da UEPG, presença fundamental devido experiência prévia como professor rondonista visto que a Equipe de ComSoc da UEPG participou pela primeira vez em 2015. Portanto, foram selecionados, na segunda quinzena de maio de 2015 , estudantes que estivessem cursando $3^{\circ}$ ou $4^{\circ}$ anos, com habilidades de produção e edição de audiovisual e/ou fotografia e que tivessem perfil de rondonista, para trabalhar em grupo e lidar com rotina de atividades. Desde a seleção, até o embarque para Cuiabá, foram feitos encontros para preparar a equipe para a Operação.

Durante toda a Operação Bororos a Equipe de ComSoc ficou alojada no $44^{\circ}$ Batalhão de Infantaria Motorizada, conhecido como Batalhão Laguna. No Batalhão a equipe dispunha de uma sala de reuniões, com acesso à internet, que funcionou como um QG para a equipe: era este o local para guardar equipamentos, planejar coberturas e produção, editar e postar materiais, etc.

Todos os dias, de 12 a 23 de julho a equipe se deslocou de Cuiabá para algumas das 15 cidades em que a Operação ocorreu. As cidades são: Acorizal, Arenápolis, Barão de Melgaço, Barra dos Bugres, Chapada dos Guimarães, Diamantino, Dom Aquino, Jangada, Juscimeira, Nortelândia, Nossa Senhora do Livramento, Poconé, Porto Estrela, Rosário Oeste e São Pedro da Cipa. Nas visitas regulares, cinco integrantes se deslocavam, sendo um professor e quatro alunos, sempre acompanhados de um motorista militar e viatura do Batalhão. Eventualmente, a equipe se deslocou com a coordenação da Operação, por conta de problemas no deslocamento. $\mathrm{E}$ ainda houve algumas coberturas especiais que visavam acompanhar a visita de alguma autoridade militar, juntamente da coordenação da Operação. Neste caso apenas um estudante, munido de várias habilidades, acompanhou.

A pauta da cobertura multimídia se dava por meio de duas principais demandas: as atividades da programação oficial, como a formatura no Batalhão, as cerimônias de abertura e encerramento, o jantar de abertura, reunião com os professores, etc., e as atividades que as IES desenvolviam nos municípios, acompanhadas por meio dos cronogramas enviados à ComSoc antes da Operação.

Como dito anteriormente, a produção se dividiu em núcleos de audiovisual, fotografia textos e redes sociais. Cada visita aos municípios redeu materiais para os quatro núcleos, e em algumas vezes, mais de um. Toda a produção, edição e veiculação foram feitas pelos, com 
Comunicação e extensão: relato de experiência da cobertura multimídia da Operação Bororos Rondon 2015

orientação dos professores e aprovação do material pela coordenação do Projeto. A produção do material, captação de imagens para vídeo e fotos e entrevistas era feita enquanto a equipe estivesse nos municípios. Já a edição e divulgação era feita de Cuiabá, no QG da ComSoc.

Todo o material, exceto o vídeo final e um conjunto de fotografias coletados de redes sociais e do grupo da Operação Bororos no aplicativo Whatsapp, que serão mais bem explicados a seguir, foi pensada para a divulgação do projeto Rondon enquanto capacitador de comunidades, com o objetivo final de alcançar o desenvolvimento sustentável. Além disso, buscou divulgar o trabalho voluntário e o espírito rondonista, que trazem universitários de todos os lugares do Brasil para participar desta Operação. E por fim, o material divulgado teve objetivo de fortalecer as alianças que o Projeto faz para garantir a viabilização das operações, como por exemplo, vínculos com outros Ministérios, Governos Estaduais e Prefeituras Municipais. A seguir elencamos uma análise dos resultados dos quatro núcleos de produção da ComSoc.

\section{O RONDON EM FOTOGRAFIAS}

A condição contemporânea da comunicação já entende como consolidada a força e onipresença das imagens, sobretudo das fotografias. Segundo Berger, "nunca houve uma forma de sociedade na história em que se desse tal concentração de imagens, tal densidade de mensagens visuais" (BERGER, 2005, p. 139).

Desta forma, dentro da Operação Bororos, uma equipe de três estudantes foram selecionados como fotógrafos. Com seus próprios equipamentos faziam a cobertura fotográfica. As captações eram focadas nas oficinas de capacitações realizadas pelos rondonistas para a comunidade. Outra orientação vinha dos cronogramas fornecidos pelas IES participantes, pelos quais os fotógrafos pautavam o que poderia render mais fotos e o que seria interessante retratar através delas.

Pode se dizer que todo o trabalho de percepção da noticiabilidade é um trabalho de pauta, mesmo que ela não se cristalize num roteiro escrito ou oral, mas se manifeste no momento em que o jornalista, diante de um fato qualquer, decida pela sua possível transformação em noticia. No que tange aos critérios de específicos, regionais ou localizados, em se tratando de grande imprensa, existe uma generalização do que diz respeito aos códigos de noticiabilidade (HENN, 1996, p.70). 
Comunicação e extensão: relato de experiência da cobertura multimídia da Operação Bororos Rondon 2015

Mesmo prevendo através de pautas, os fotógrafos estavam preparados para caso elas caíssem, ou seja, fossem canceladas por algum motivo. Muitas vezes chegava-se ao município para fotografar algo e percebia-se que outro fato pode render mais.

Além das fotografias que acompanhavam as notas e notícias, outro recurso usado foi o de fotolegenda, que é caracterizada por vir juntamente com a imagem, um texto de no máximo 400 caracteres (tamanho definido pelo fotógrafos da equipe). No texto são dadas informações que complementam a imagem e/ou depoimentos e impressões dos entrevistados.

Este último conteúdo convocada, muitas vezes, um retrato do rondonista ou da comunidade. O retrato é o tipo de foto onde o destaque é o rosto - de uma ou mais pessoas, posado ou não -. Surgiu por volta do ano de 1750 com a ascensão da classe média. Os burgueses eram retratados, em forma de pinturas, para mostrar a importância que tinham na sociedade e com o tempo, se popularizou, trazendo rostos diversos.

No processo de edição, as fotografias feitas eram selecionadas, tratadas se fosse preciso e colocadas em um molde, caso fosse para fotolegenda. Esse molde foi criado pelos fotógrafos, para que houvesse um padrão visual. As fotos para acompanhar os textos de notas e notícias, eram feitas pensadas juntamente com quem escreveria a matéria. Em geral, quatro fotos acompanhavam cada texto.

As fotolegendas eram postadas diretamente no Facebook do Projeto Rondon. Já as fotos que acompanhavam as matérias primeiramente iam para o site oficial para depois serem compartilhadas via Facebook, processo muito comum na fotografia digital, já que segundo Wesrbrook (2002, s.p.) a fotografia digital “abriu novas jurisdições por reunir notícias, de pequenos e pessoais boletins informativos, para blogs on-line. Estas novas jurisdições significam um mercado aumentado e um passo acelerado para a transmissão de notícias através de imagens fotográficas".

As mídias digitais utilizadas como principal canal de comunicação da ComSoc da Operação Bororos, fez com que rondonistas desta e de outras operações, seus respectivos familiares espalhados pelo Brasil, e a comunidade dos municípios participantes pudessem acompanhar tudo através da internet: em questão de segundos, todos podiam ver histórias contadas através de imagens. 
Comunicação e extensão: relato de experiência da cobertura multimídia da Operação Bororos Rondon 2015

\section{AUDIOVISUAL}

Durante a Operação Bororos, a equipe de comunicação visitou as 15 cidades que integraram a operação, e produziram o total de 25 vídeos. A produção de vídeos durante a Operação Bororos do Projeto Rondon 2015 foi pensada em conjunto, pelos 10 integrantes da ComSoc. O único material audiovisual com entrega obrigatória, ao final da operação, era o vídeo final, mas outros materiais (vídeos curtos e diários) foram produzidos pela equipe de comunicação. Essas produções também serviram como forma de divulgar individualmente as atividades da Bororos. Um deles que se diferencia dos demais é uma entrevista com o historiador Cacá de Souza, especializado na história de Marechal Cândido Rondon. Em alguns casos nos quais havia atividades paralelas de cada uma das IES foram feitos dois vídeos, separados por IES.

Foi consenso em reunião de pauta realizada no primeiro dia em Cuiabá ( 9 de julho), que a produção seria feita de forma que a figura do repórter não apareceria no vídeo, ou seja, a passagem, "apresentação do repórter na arena dos acontecimentos" (VALLE, 2007, p.1), não seria usada, e nem o off (narração do vídeo), elementos comuns às notícias em telejornalismo. Nesse caso, toda a produção deveria seguir o mesmo padrão de vídeo "autoexplicativo", ou seja, a partir das próprias entrevistas e imagens de apoio, as atividades realizadas na cidade, pelas respectivas equipes deveriam ser contadas por si só.

A opção de vídeos mais dinâmicos sem o repórter também foi escolhida pelo tempo determinado para cada produção: em média de um a dois minutos para os vídeos curtos. Ou seja, o material precisaria ser direto. Outro padrão estipulado pela equipe foi a vinheta de abertura e os GCs usados (identificação da fonte na entrevista). A vinheta de abertura foi elaborada previamente e utilizada em todos os vídeos. Já o GC era na cor branca, com fonte tamanho 80 para nome, em caixa alta, e 70 para descrição da função, conforme foco da entrevista.

A divisão de qual aluno ficaria responsável pela produção era feita um dia antes da viagem, geralmente no período da noite. Dos oito alunos que integraram a equipe, sete auxiliaram; cada um em uma medida e em algum momento, na produção do audiovisual. Seja na elaboração de vídeos curtos ou na captação de imagens para o vídeo final.

Durante a última semana da Operação, os esforços passaram a se concentrar na produção do vídeo final, direcionado aos rondonista, para o encerramento das atividades. $O$ material deveria trazer elementos da Operação Bororos e do espírito do rondonista. O vídeo teve a duração de um pouco mais que oito minutos, e foi dividido em três partes. A primeira dando ênfase na receptividade das comunidades com os universitários, a segunda com o que é ser 
Comunicação e extensão: relato de experiência da cobertura multimídia da Operação Bororos Rondon 2015

rondonista e se relacionar com a comunidade, e a terceira e última mostrando os bons frutos da atividade voluntária e extensionista proporcionada pelo Rondon.

\section{PRODUÇÃO TEXTUUAL}

A produção de texto para a Operação Bororos, do Projeto Rondon, contou com a participação de seis estudantes da ComSoc. Este núcleo também utilizou, para nortear seu trabalho, cronograma referente às atividades a serem desenvolvidas pelas IES durante a Operação, cuja pauta conduziu a produção de notas e notícias.

Nesse processo, a seleção e divisão das pautas se basearam em critérios de noticiabilidade e valores notícias pré-estipulados por Wolf (2003) e Traquina (2001), por compreender-se que o jornalismo atua como um serviço de interesse público. E, portanto, foi considerado o compromisso com a divulgação das atividades de extensão das universidades juntos às comunidades que acolheram a atuação do Projeto Rondon.

Conforme Wolf (2003, p. 202) “valores-notícia são critérios de relevância difundidos ao longo de todo o processo de produção e estão presentes tanto na seleção das notícias como também permeiam os procedimentos posteriores, porém com importância diferente". Por isso, estipulou-se um calendário de apuração que privilegiava trabalhos cruciais de cada uma das IES igualmente, de modo a pauta-las na agenda midiática produzida pela ComSoc no canais de comunicação do Projeto Rondon.

De acordo com os pesquisadores McCombs e Shaw (1972), existem três tipos de agendas: pública, política e midiática, e, se uma temática for abordada por alguma delas e obtiver uma repercussão razoável, consequentemente atingirá as demais e o resultado são ações concretas no que se refere à disseminação do debate relacionado à pauta e, desta forma, refletirá no cenário das políticas públicas referentes, também, a ela.

O cuidado de inserir atividades de todas as IES foi, também, pensado para as outras plataformas de atuação. No entanto, nas produções diárias de texto, cada uma das cidades visitadas e as duas respectivas universidades que prestavam serviços de capacitação no local, tiveram suas pautas trabalhadas em textos individuais, para que nenhum detalhe importante fosse deixado de lado no processo de construção da notícia. 
Comunicação e extensão: relato de experiência da cobertura multimídia da Operação Bororos Rondon 2015

O gênero jornalístico escolhido para os textos sobre cada cidade foi o informativo, pois é um formato que pede o tratamento de fatos específicos com foco em sua pertinência e valor social, de forma clara e concisa. Exceto em situações específicas, em que o contexto da informação faria diferença para o desenvolvimento do texto, usou-se do gênero interpretativo, mais especificamente, jornalismo literário. A proposta nesse segundo caso foi, justamente, criar uma ambiência para o leitor, oferecendo a ele a possibilidade de uma leitura mais pessoal sobre o assunto.

\section{MÍDIAS SOCIAIS}

Conforme dito anteriormente, toda a produção feita pela Equipe de Comunicação da era divulgada na página do Projeto Rondon no Facebook e replicada no Twitter, notas e notícias eram postadas no site oficial do Projeto Rondon e os vídeos eram postados no canal oficial no Youtube. A escolha das plataformas foi feita pela Coordenação de Comunicação Social do Rondon, seguindo o modelo de outras operações. E tal escolha faz sentido no cenário atual.

A Internet não é simplesmente uma tecnologia; é o meio de comunicação que constitui a forma organizativa de nossas sociedades; é o equivalente ao que foi a fábrica ou a grande corporação na era industrial. A internet é o coração de um novo paradigma sociotécnico, que constitui na realidade a base material de nossas vidas e de nossas formas de relação, de trabalho e de comunicação. O que a internet faz é processar a virtualidade e transformá-la em nossa realidade, construindo a sociedade em rede, que é a sociedade em que vivemos. (CASTELLS, 2003, p.287)

Como forma de organizar a divulgação do material criamos as hashtags \#ProjetoRondon e \#OperaçãoBororos, as quais foram adicionadas a todos os posts das redes sociais feitos pela ComSoc. A postagem ou agendamento no Facebook e no Youtube ficava a cargo do autor do texto/vídeo/fotolegenda. As hashtags foram divulgadas aos demais rondonistas, antes do efetivo início das atividades nos município, como forma de compor um motor de busca para identificar a produção de materiais feitos por outros rondonistas.

O Facebook era o nosso meio mais utilizado, pois centralizava todos os canais e ainda possuía conteúdo exclusivo. Quando o texto era publicado no site - os responsáveis por essa plataforma eram os coordenadores - era preciso postar o link no Facebook, com um teaser e os créditos dos autores do texto e da foto. Segundo o Manual de Comunicação da Secretaria de Comunicação do Senado, Teaser significa: 
Comunicação e extensão: relato de experiência da cobertura multimídia da Operação Bororos Rondon 2015

1. Breve chamada de uma notícia. Pode ser veiculado logo após a manchete para veiculação de informação complementar. [...] 2. Teaser - em_inglês aquele que provoca (provocante), do_verbo to tease, provocar - é uma técnica usada em marketing para chamar a atenção para uma campanha publicitária, aumentando o interesse de um determinado público-alvo a respeito de sua mensagem, por intermédio do uso de informação enigmática no início da campanha. (SENADO FEDERAL, 2015, web)

Quando o vídeo era publicado no Youtube, era seguida a mesma lógica, com link divulgado da página do Projeto no Facebook, juntamente de um teaser e créditos de produção. O nome do vídeo seguia um padrão: Operação Bororos (Rondon 2015), seguido do nome da cidade e, quando era feito mais de um vídeo por município, o nome da IES.

Já as fotolegendas eram produções exclusivas para o Facebook. A postagem contava apenas com os créditos de texto e foto e as hashtags usuais (\#OperaçãoBororos e \#ProjetoRondon). Alguns outros conteúdos também eram exclusivos das redes sociais, como eventos pontuais da Operação, que se apresentavam por meio de um teaser e uma fotografia.

Como toda produção passava por uma aprovação da Coordenação de Comunicação Social, criou-se uma dinâmica de aprovação, com horários padrões para as postagens. Fotolegendas eram postadas às $9 \mathrm{~h}, 15 \mathrm{~h}$ e $19 \mathrm{~h}$, textos já postados no site do Rondon eram publicados na página do Facebook às $11 \mathrm{~h}$ e $21 \mathrm{~h}$ e os vídeos, já subidos no canal do Youtube às $13 \mathrm{~h}$ e $17 \mathrm{~h}$.

\section{CONSIDERAÇÕES FINAIS}

A ideia central deste artigo foi discutir o processo produtivo dos materiais multimídia produzidos durante a cobertura das atividades rondonistas da Operação Bororos. Para isso, estruturou-se uma discussão a partir dos quatro núcleos de produção (textos, audiovisual, fotografias e mídias sociais) para esmiuçar a produção e aprofundar a discussão.

As fotografias são verdadeiros registros para a memória do Projeto, dos rondonistas e da comunidade. O olhar observador, às vezes, mostra coisas que passam despercebidas no dia a dia. Sendo assim, é possível perceber a importância do trabalho dos fotógrafos dentro de uma Equipe de Comunicação do Projeto Rondon.

E, de forma geral, toda a produção mostrou-se não efêmera, mas, sim, com caráter documental das rotinas e atividades rondonistas, priorizando mostrar a capacitação para o 
Comunicação e extensão: relato de experiência da cobertura multimídia da Operação Bororos Rondon 2015

desenvolvimento sustentável das comunidades. Outra contribuição foi representar as diversas instituições acionadas para a execução do Projeto Rondon: Instituições de Ensino Superior, diversos Ministérios, Forças Armadas, Governos Estaduais e Prefeituras Municipais.

A experiência enquanto rondonistas ofereceu aos estudantes da ComSoc a chance de aplicar, no dia a dia de uma rotina jornalística, os conhecimentos adquiridos em sala de aula. $\mathrm{O}$ exercício do jornalismo vai além dos conceitos e suposições, é uma via de mão dupla em que a prática depende da teoria e vice e versa. Nesse aspecto, a relevância profissional de desenvolver o trabalho de comunicação durante as duas semanas da Operação Bororos, além de contribuir com a causa social e divulgação do Projeto Rondon, auxiliou na capacitação dos estudantes para o mercado de trabalho.

\section{REFERÊNCIAS}

BERGER, John.A. Modos de ver. Barcelona: Asa, 2005.

CASTELLS, Manuel. Internet e sociedade em rede. In: Dênis de Moraes (org.), Por uma outra comunicação - mídia, mundialização cultural e poder. Rio de Janeiro, Ed. Record, 2004.

SENADO FEDERAL. Manual de Comunicação da Secom. Disponível em:

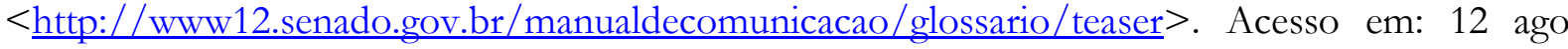
2015.

HENN, Ronaldo Cesar. A pauta e a noticia: uma abordagem semiótica. Canoas: Ed. ULBRA, 1996.

TRAQUINA, Nelson. O estudo do jornalismo no século XX. São Leopoldo, RS: Editora Unisinos, 2001.

VALLE, Flávio Pinto. Reflexões sobre o papel da Passagem no Telejornalismo, 2007. Disponível em: <http://www.fafich.ufmg.br/gris/images/Reflexões $\% 20$ sobre $\% 20 \mathrm{o} \% 20$ papel $\% 20 \mathrm{da} \% 20 \mathrm{Passag}$ em\%20no\%20telejornalismo.pdf>. Acesso em: 12 ago 2015.

WOLF, Mauro. Teorias da comunicação de massa. São Paulo: Martins Fontes: 2003. 